\title{
The Fuel Economy Analysis of Series Hybrid Electric Bus with Different Energy Storage Devices
}

\author{
Xiaogang $\mathrm{Wu}^{1}$, Chen $\mathrm{Hu}^{1}$, Jiuyu $\mathrm{Du}^{2}$ and Meilan Zhou ${ }^{1}$ \\ ${ }^{1}$ College of Electrical \& Electronic Engineering, Harbin University of Science \\ and Technology, Harbin, China \\ ${ }^{2}$ Department of Automotive Engineering, Tsinghua University, Beijing, China \\ xgwu@hrbust.edu.cn
}

\begin{abstract}
Two kinds of energy strategy devices of series hybrid electric bus, Ni-MH battery and super-capacitor, are used in this paper. The influence of using different energy storage devices on fuel economy of the series hybrid electric system is analyzed by power flow method. The simulation results show that the system with super-capacitor can effectively improve the efficiency of the braking energy recovery, in condition of a certain Chinese city driving cycle and the average power of the electric auxiliary power unit is $5 \mathrm{~kW}$.
\end{abstract}

Keywords: Series Hybrid Electric Bus, Energy Storage Device, Fuel Economy, Potential, Comparative Analysis.

\section{Introduction}

The series hybrid electric system has a large proportion in the amount of the new hybrid electric bus. Although the parts of the series hybrid electric system (for example: generator, battery, traction motor) add the weight of the bus, the series configuration will not influence the dynamic performance observably for the bus is already heavy enough. Meanwhile, the series hybrid electric system with APU can effectively recover the braking energy.

The configuration of the series hybrid electric system is shown in Figure 1.

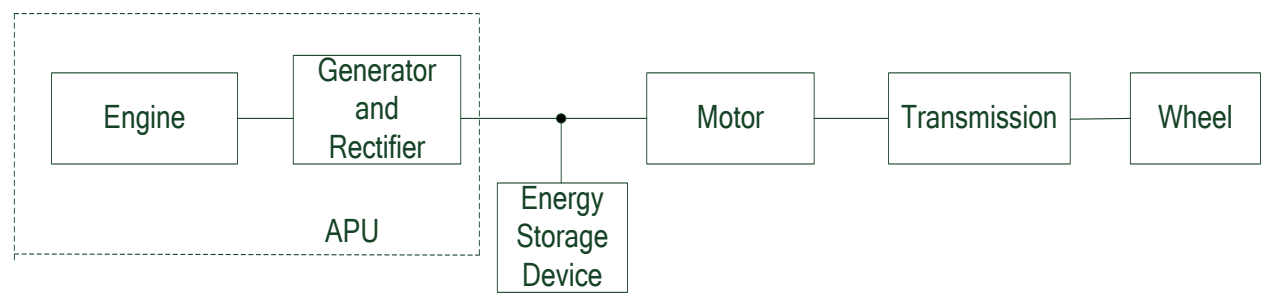

Figure 1. Series hybrid electric system

Engine is integrated with the generator to be named as Auxiliary Power Unit (APU) and the APU output is transferred directly to energy storage device or traction motor. Traction motor works to drive the bus in motoring mode or recover the braking energy into electric energy in generating mode. In general, the energy of the series hybrid electric system is distributed by vehicle controller. The vehicle controller determines 
the distribution between the APU and energy storage device through the power requirement of the driving cycle and conditions of different parts. This research is based on powertrain of the series hybrid electric bus (as is shown in Figure 1) The APU is constituted of diesel engine, electric excitation generator and three-phase uncontrollable rectifier (as is shown in Figure 2). The APU output power is transmitted to connect energy storage device and load [1-2].

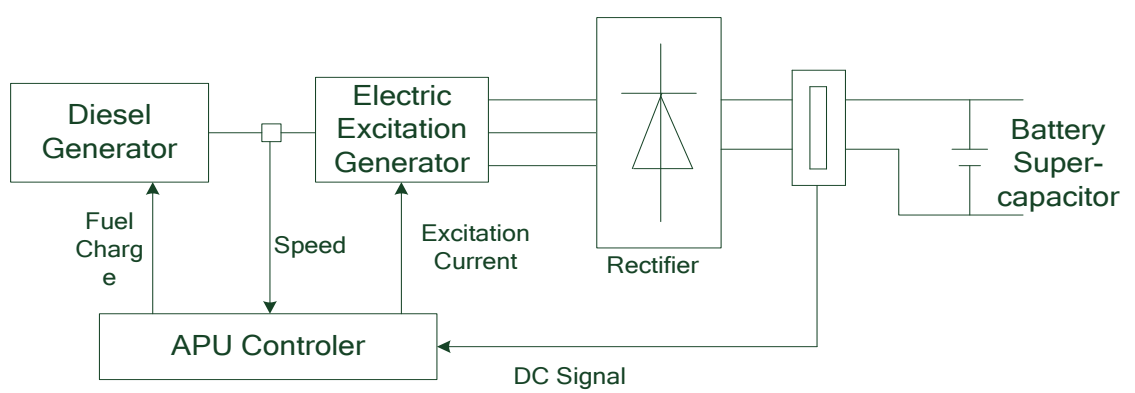

Figure 2. APU configuration

Now the studies of the series hybrid electric bus mainly focus on configuration analysis and energy management strategy. In configuration analysis, literature [3] made optimization design for the traction motor and energy storage device of the army's suspension, using super-capacitor and battery as energy storage devices to improve the battery life. Literature [4] put forward a system of diesel engine, generator, lead-acidbattery, and super-capacitor and made the study by power follow energy management algorithm for the four-wheel driving series hybrid electric bus. Both literature [5] and [6] studied the designs of DC/DC power converter and control method for the configuration of battery and super-capacitor. Literature [7] put forward a configuration using GT (Gas Turbine) as APU prime motor for series hybrid electric min-bus. In energy management strategy, the mainly algorithms are instantaneous optimization algorithm based on the minimum fuel consumption, fuzzy logic algorithm based on complex rules, global optimization algorithm based on established driving cycle. Literature [8] put forward an optimization algorithm based on the minimum fuel consumption rule. The efficiency is improved by $1.6 \%$ 5\% compared with conventional thermostat control method. Literature [9-10] studied the change of engine working points and optimization efficiency area based on sliding mode controller and improved the energy efficiency of the series hybrid electric bus for High Mobility Multipurpose Wheeled Vehicle. Literature [11] put forward an algorithm of engine-generator torque and speed based on optimization track for the series hybrid electric bus. Literature [1213] improved the energy efficiency of the series hybrid electric system by new control method based on equivalent consumption minimization strategy. Literature [14] put forward a selection and control method and studied the minimum fuel consumption strategy in determined condition for the series tracked vehicle. Literature [15] put forward an energy management strategy that using fuzzy logic algorithm to confirm battery condition and make sure that the engine is working at high fuel efficiency area to avoid battery over discharged for plug-in series hybrid vehicle. Literature [16] used improved dynamic programming to optimize the APU of the series hybrid electric system and power battery output power. The operation time is reduced as well as the fuel consumption. 
In energy management strategy, most studies focus on optimizing the engine working points and efficiency area of engine. But the fuel economy analysis of the series hybrid electric bus is seldom reported in Chinese city driving cycle. Although literature [17] analyzed and compared the system efficiency in the public transit driving cycle, braking energy recovery, idle shutdown and the electric auxiliary system of the series hybrid electric system using 75Ah lead-acid battery. The fuel economy of different energy storage devices has never been analyzed.

This paper compares the economy influence of series hybrid electric bus with different energy storage devices of super-capacitor and Ni-MH battery. The fuel economy improvement of the series hybrid vehicle using the super-capacitor compared with conventional fuel bus and the series hybrid electric bus that using Ni-MH battery is also obtained.

\section{Operation Condition Analysis and Formulating Energy Management Strategy}

This paper uses a certain Chinese city driving cycle (as is shown in Figure 3) to analyze the economy of the series hybrid electric system.

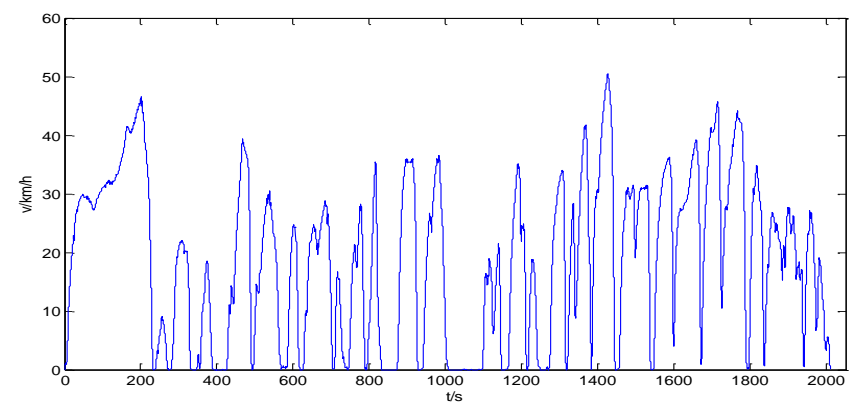

Figure 3. Certain Chinese city driving cycle

As is shown in Table 1 , the driving cycle duration is $2010 \mathrm{~s}$, covering $10.56 \mathrm{~km}$, the maximum speed is $50.55 \mathrm{~km} / \mathrm{h}$, the average speed is $18.91 \mathrm{~km} / \mathrm{h}$ (considering idle), idle proportion is $12.64 \%$.

Table 1. The characteristic value

\begin{tabular}{|c|c|}
\hline Duration time $/ \mathrm{s}$ & 2010 \\
\hline Trip mileage $/ \mathrm{km}$ & 10.56 \\
\hline Maximum speed $/ \mathrm{km} / \mathrm{h}$ & 50.55 \\
\hline Average speed $/ \mathrm{km} / \mathrm{h}$ & 18.91 \\
\hline Maximum acceleration $/ \mathrm{m} / \mathrm{s}^{-2}$ & 1.26 \\
\hline Maximum deceleration $/ \mathrm{m} / \mathrm{s}^{-2}$ & -2.75 \\
\hline Average acceleration $/ \mathrm{m} / \mathrm{s}^{-2}$ & 0.27 \\
\hline Average deceleration $/ \mathrm{m} / \mathrm{s}^{-2}$ & -0.37 \\
\hline Idle time $/ \mathrm{s}$ & 254 \\
\hline Parking times $/$ times & 22 \\
\hline
\end{tabular}


Energy management strategy may increase the fuel economy of the series hybrid electric system. As mainly studying the fuel consumption influence of the energy storage device, this paper chooses power follow algorithm based on rules. As Ni-MH battery is in the best working condition with $40 \% \sim 70 \%$ SOC, the energy distribution curve based on SOC is mainly in this interval.

In the process of energy distribution, APU, energy storage device and traction motor fit formula (1). The objective power of APU is determined after the power provided by energy storage device is determined.

$$
P_{A P U}=P_{m o t}-P_{b a t}+P_{a}
$$

Where, $P_{\mathrm{APU}}$ is the APU output power, $P_{\text {mot }}$ is the traction motor controller inlet power, $P_{\text {bat }}$ is the energy storage device power, $P_{\mathrm{a}}$ is the auxiliaries consumption power, auxiliaries include air condition, battery heat management system, interior heating system, lighting and control system, steering and braking consumption.

\section{Simulation Results and Analysis}

To effectively analyze the economy of the series hybrid electric bus, this paper analyzes the influence of different energy storage devices on the fuel economy.

The model data used in simulation is shown in Table 2.

\section{Table 2. Series hybrid electric bus simulation model data}

\begin{tabular}{|c|c|}
\hline Length, width and height(mm) & $11980 \times 2550 \times 3180$ \\
\hline Mass(kg) & 12900 \\
\hline Engine type & ISDE160-30 \\
\hline $\begin{array}{c}\text { Engine rated power(kW) } \\
\text { speed(r/min) }\end{array}$ & 2500 \\
\hline $\begin{array}{c}\text { Engine maximum torque (N·m) } \\
\text { Engine maximum torque rotary } \\
\text { speed(r/min) }\end{array}$ & 600 \\
\hline Generator type & 1300 \\
\hline $\begin{array}{c}\text { Generator maximum rotary } \\
\text { speed(r/min) }\end{array}$ & 1500 \\
\hline $\begin{array}{c}\text { DC output voltage with full-wave } \\
\text { rectification(V) }\end{array}$ & $360 \sim 460$ \\
\hline $\begin{array}{c}\text { Energy storage device } \\
\text { UCapacitor } 11.7 \mathrm{~F}\end{array}$ \\
\hline Traction motor type & JD147A \\
\hline $\begin{array}{c}\text { Traction motor maximum rotary } \\
\text { speed(r/min) }\end{array}$ & 4500 \\
\hline $\begin{array}{c}\text { Traction motor highest/rated } \\
\text { power(kW) }\end{array}$ & $160 / 80$ \\
\hline Traction motor maximum torque & $\geq 1300 \mathrm{~N} . \mathrm{m}$ \\
\hline Transmission main reduction ratio & 6.333 \\
\hline
\end{tabular}


It is assumed that air condition, power steering and other auxiliaries worked in electric auxiliary mode, and the average power is $5 \mathrm{~kW}$. To further accurately calculate the fuel economy, the simulation sets the same SOC value in both start and stop point.

Figure 4 is the parts working condition of the hybrid system with Ni-MH battery. Figure 4 shows that, in one driving cycle, APU output power changing follows the power demands. The charge and discharge ratio of $\mathrm{Ni}-\mathrm{MH}$ battery is controlled below $3.5 \mathrm{C}$, the fuel consumption in simulation is $31.42 \mathrm{~L} / 100 \mathrm{~km}$.
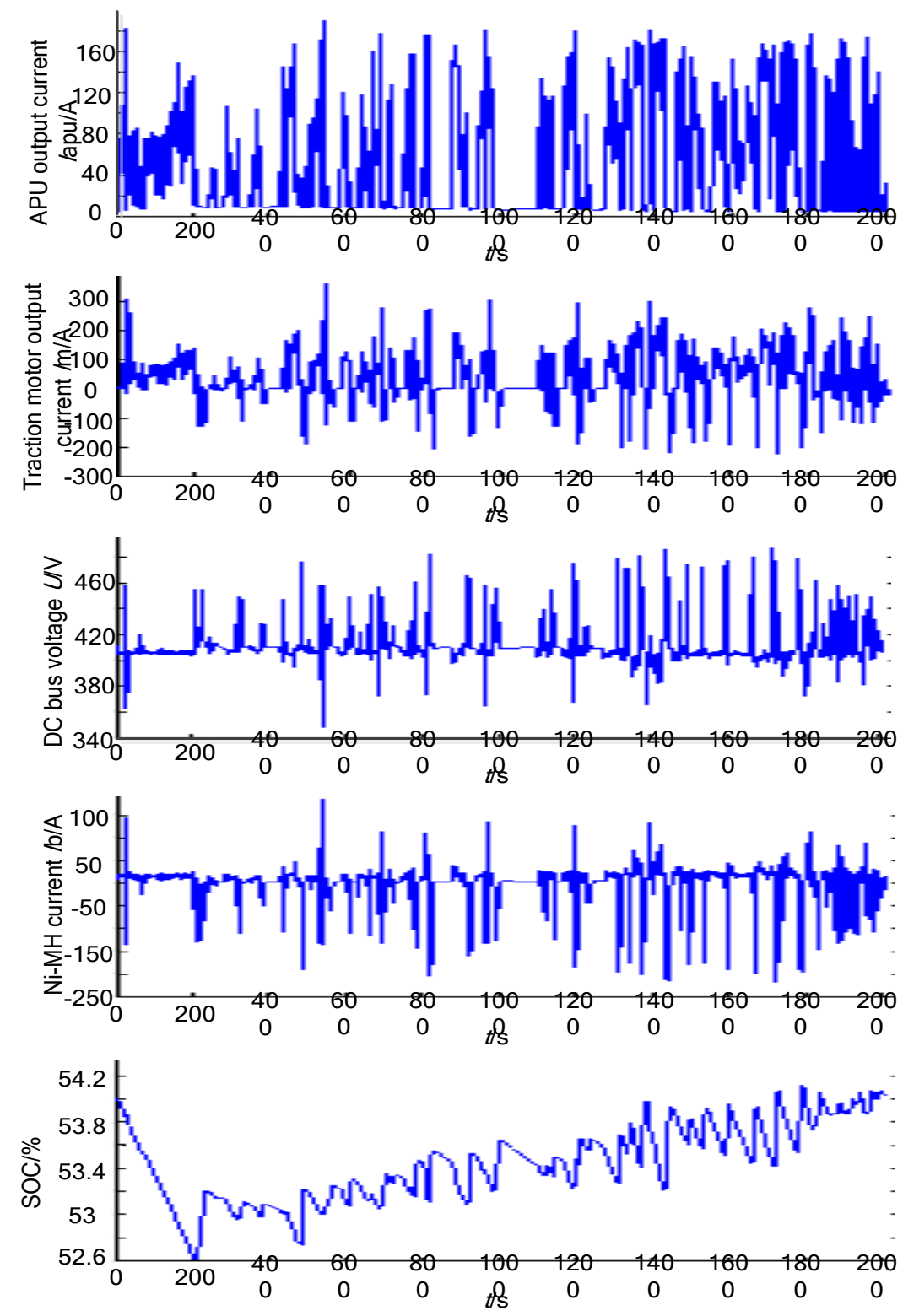

Figure 4. Parts of the series hybrid electric system changing curve with $\mathrm{Ni}-\mathrm{MH}$ battery

Figure 5 shows the distribution of the engine working points. The engine mainly works in the trajectory that is given in the power follow energy management. 


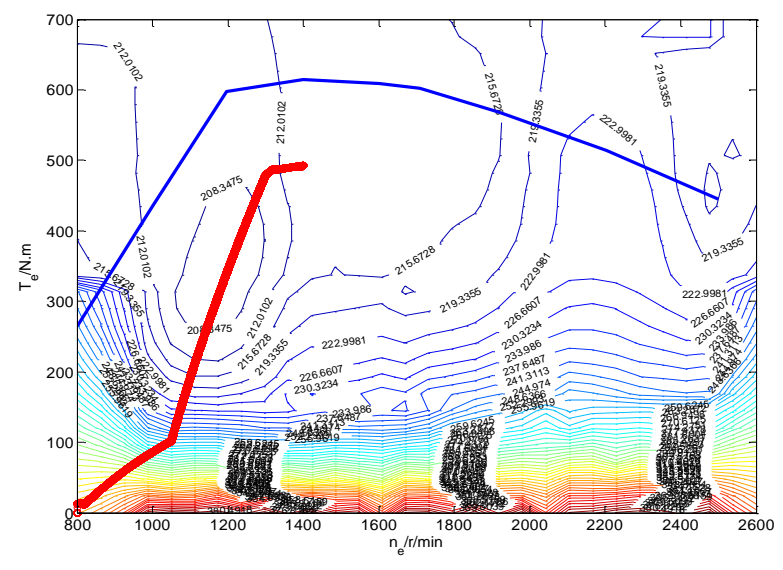

Figure 5. The engine working points distribution with Ni-MH battery

The energy flow in simulation is shown in Figure 6.

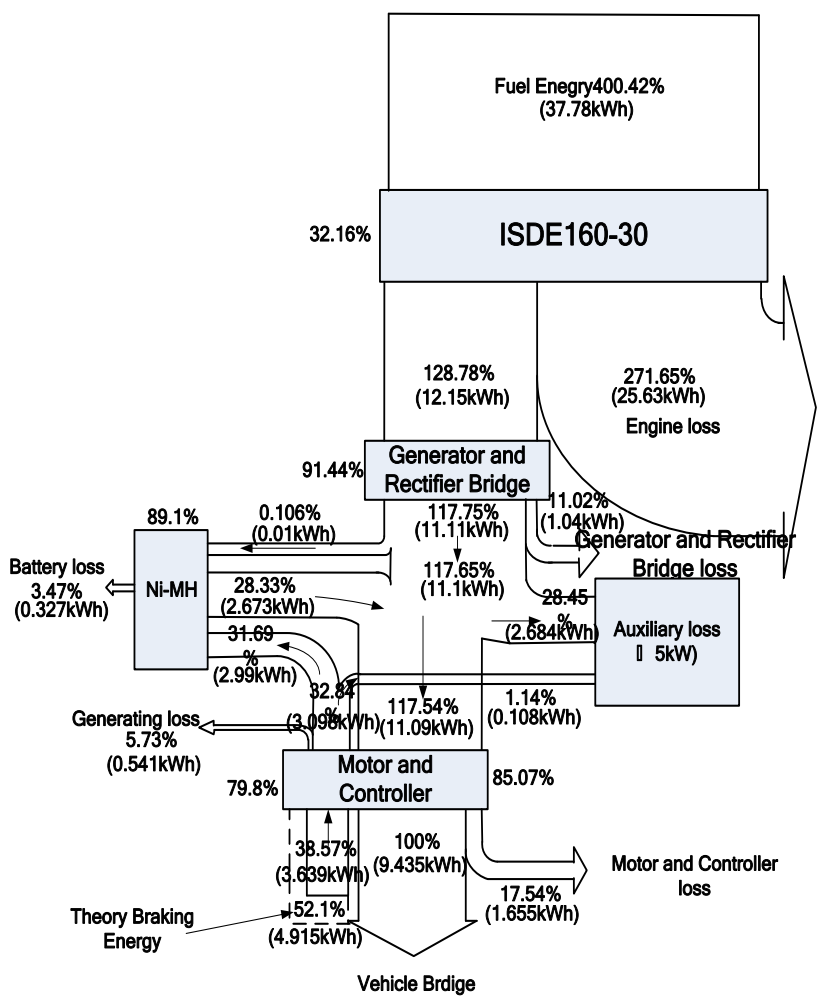

Figure 6. The hybrid system energy flow chart with Ni-MH battery

Figure 6 shows that, the charge and discharge resistance is relatively higher that of using Ni-MH battery. The system energy efficiency of the device can only reach $89.1 \%$.

Figure 7 is the parts working condition of the energy storage device with supercapacitor and APU using load following control method. Figure 7 shows that, as using super-capacitor, the charge and discharge ratio reaches above $4 \mathrm{C}$ and the fuel consumption is $29.52 \mathrm{~L} / 100 \mathrm{~km}$. 

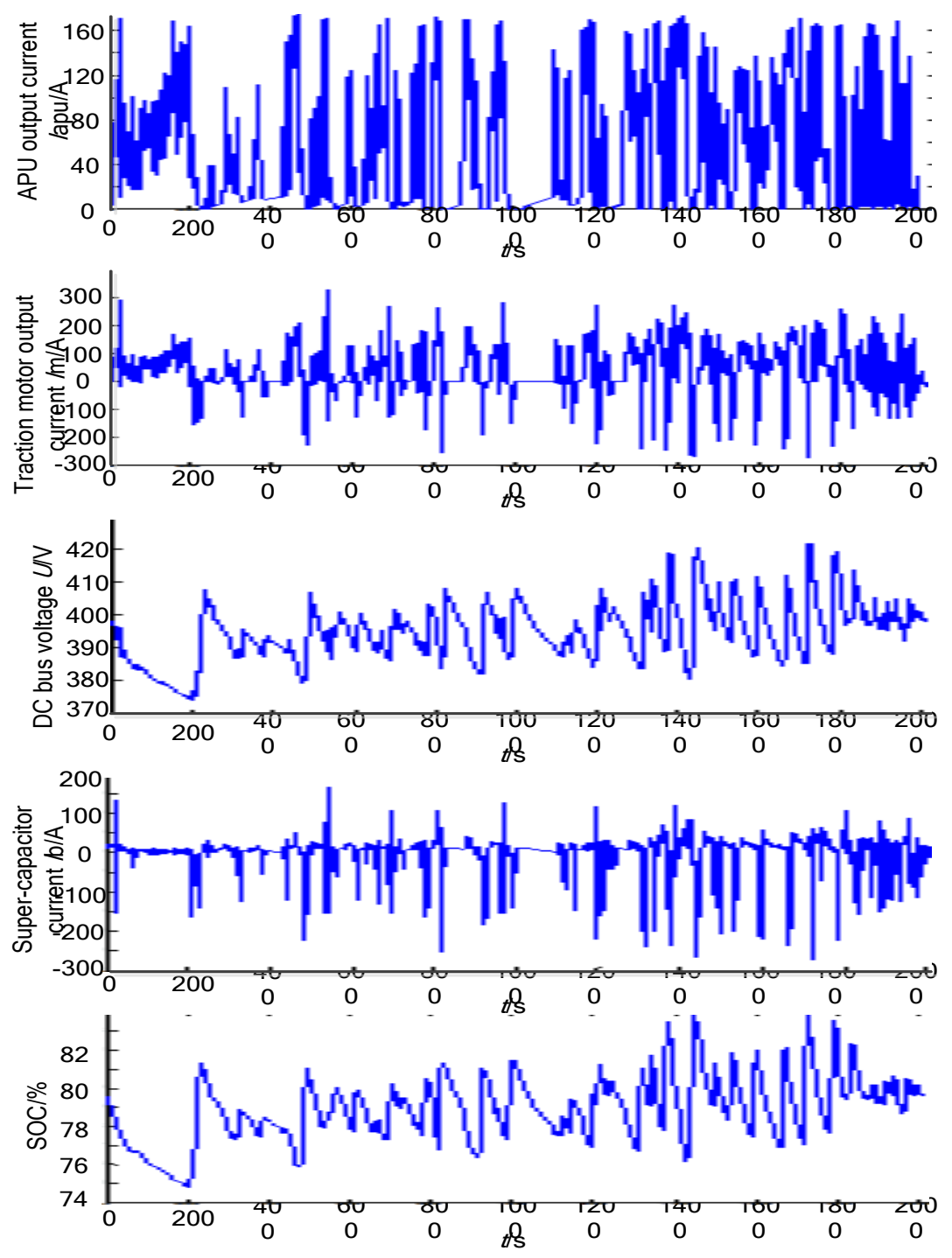

Figure 7. Parts of the series hybrid electric system changing curve with supercapacitor

Figure 8 is the distribution of the engine working points with super-capacitor. The energy flow is shown in Figure 9. The system energy efficiency of the device is improved and can reach $99.1 \%$. The fuel energy is reduced and the fuel economy of the hybrid electric system is improved. 


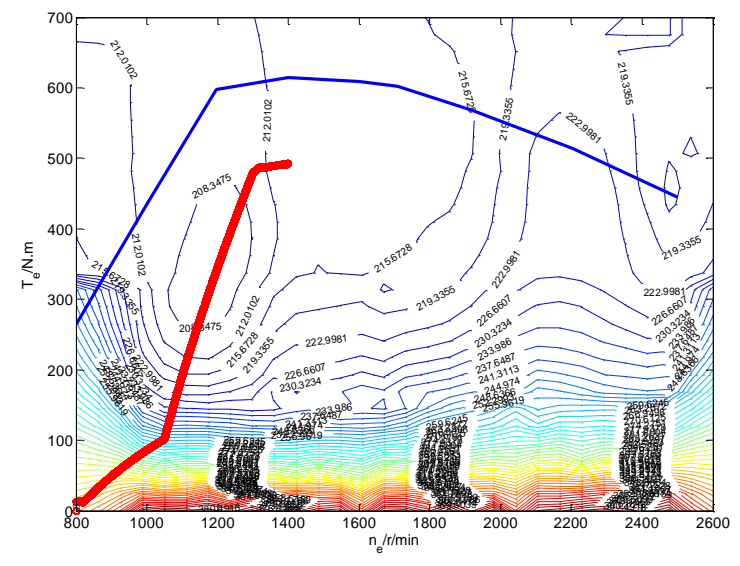

Figure 8. The engine working points distribution with super-capacitor

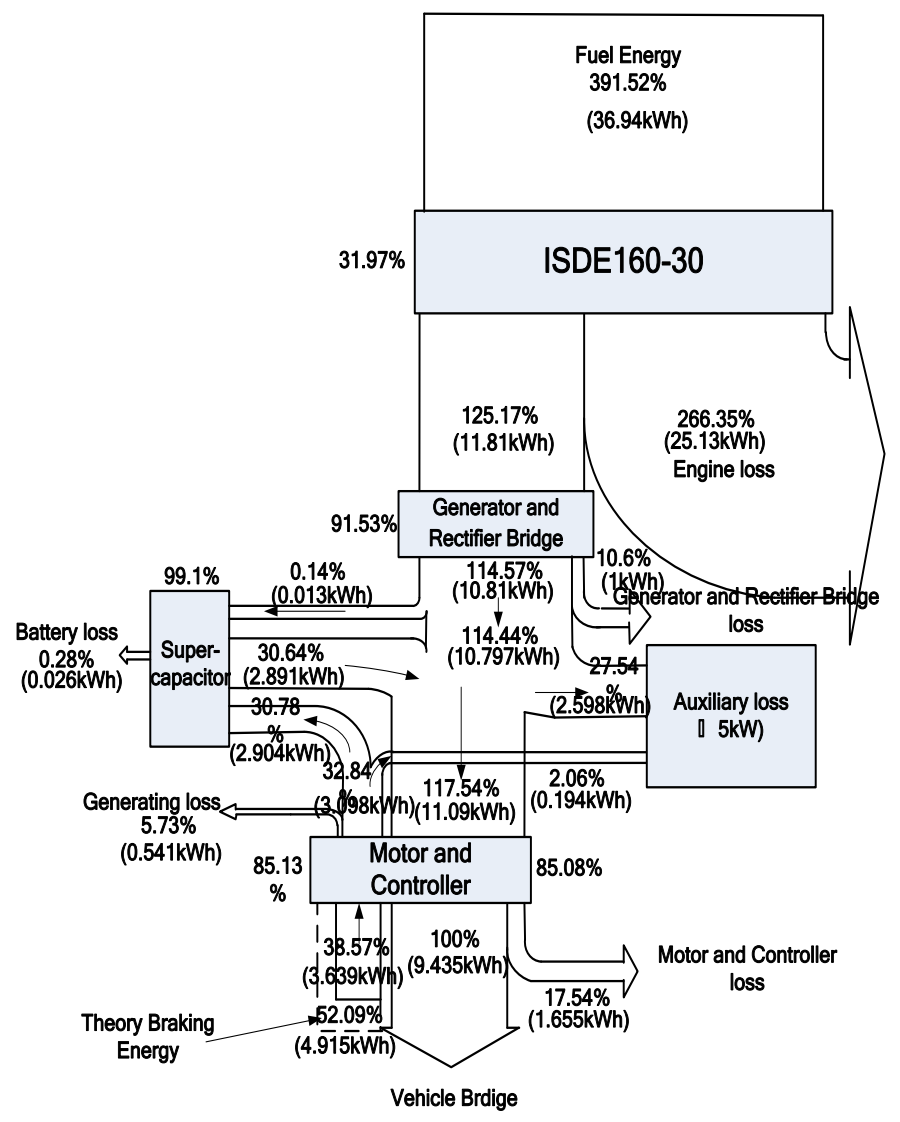

Figure 9. The hybrid system energy flow chart with super-capacitor

Based on simulation results, the power flow characteristics of components are analyzed (as is shown in Table 3 ).

Table 3 shows that, the loss of the energy storage device of the series hybrid electric bus using super-capacitor is reduced by $0.8 \%$. The fuel economy is increased by $6.05 \%$ compared with the series hybrid electric system with Ni-MH battery. The fuel economy 
is increased by $16.14 \%$ compared with the conventional fuel bus (the auxiliary average power of the conventional bus is $4 \mathrm{~kW}$ ).

Table 3. The energy and loss of the parts of the series hybrid electric system with different energy storage devices

\begin{tabular}{|c|c|c|c|}
\hline Bus(Energy storage device) type & Ni-MH batter & $\begin{array}{c}\text { Super- } \\
\text { capacitor }\end{array}$ & $\begin{array}{c}\text { Conventional } \\
\text { fuel bus }\end{array}$ \\
\hline Fuel energy & $400.42 \%$ & $391.2 \%$ & $519.89 \%$ \\
\hline Feedback energy in theory & $52.1 \%$ & $52.09 \%$ & \\
\hline Braking feedback recovery energy & $32.84 \%$ & $32.84 \%$ & \\
\hline Engine loss & $271.65 \%$ & $266.35 \%$ & $380.21 \%$ \\
\hline Generator and rectifier loss & $11.02 \%$ & $10.6 \%$ & \\
\hline Energy storage device loss & $3.47 \%$ & $0.28 \%$ & \\
\hline Generating loss & $5.73 \%$ & $5.73 \%$ & \\
\hline Generator driving loss & $17.54 \%$ & $17.54 \%$ & $33.04 \%$ \\
\hline Auxiliary loss & $28.45 \%$ & $27.54 \%$ & $100 \%$ \\
\hline Vehicle driving energy & $100 \%$ & $100 \%$ & 35.2 \\
\hline Fuel consumption L/100km & 31.42 & 29.52 & \\
\hline Fuel saving ratio compared with & $10.74 \%$ & $16.14 \%$ & \\
\hline conventional fuel bus & & & \\
\hline
\end{tabular}

\section{Conclusion}

The actual test data of certain Chinese city is chosen as the driving cycle of the simulation in this paper. The load following method is used as energy management strategy. Two different energy strategy devices, Ni-MH battery and super-capacitor, can be used in the system. The device has two kinds of energy recovery methods, idle shutdown and braking energy recovery. The fuel economy potential of series hybrid electric system is analyzed.

Based on the simulation results, it can be concluded that if using the super-capacitor as energy storage device, the fuel economy is increased by $6.05 \%$ compared with the hybrid system with Ni-MH battery, the fuel economy is increased by $16.14 \%$ compared with the conventional fuel bus.

\section{Acknowledgements}

This work is supported by National Natural Science Foundation (NNSF) of China(Grant No.51105220), funded by the Postdoctoral research startup of Heilongiiang Province(Grant No.LBHQ12068).

\section{References}

[1] T. Ciccarelli and R. Toossi, "Assessment of hybrid configuration and control strategies future metropolitan/urban transit bus", Final Report of California State University Long Beach, (2002).

[2] G. Cao, L. Lu, H. Xiong, J. Li, et al., "Experimental study on fuel economy of diesel based series hybrid power train for city bus", Chinese Internal Combustion Engine Engineering, vol. 30, no.7, (2009), pp. 1-6.

[3] Y. Gao and M. Ehsani, "Parametric design of the traction motor and energy storage for series hybrid off-road and military vehicles", IEEE Transactions on power electronics, vol. 21, no. 3, (2006), pp. 749-755.

[4] H. Yoo and S. -K. Sul, Y. Park and J. Jeong, "System integration and power-flow management for a series hybrid electric vehicle using supercapacitors and batteries", IEEE Transactions on Industry Applications, vol. 44, no. 1, (2008), pp. 108-114. 
[5] M. Bailo, H. Gualous, F. Gustin, B. Dakyo, et al., "DC/DC converter design for supercapacitor and battery power management in hybrid vehicle applications-polynomial control strategy", IEEE Transactions on Industrial Electronics, vol. 57, no. 2, (2010), pp. 587-597.

[6] A. Xu, S. Xie and X. Liu, "Dynamic voltage equalization for series-connected ultracapacitors in EV/HEV Applications", IEEE Transactions on Vehicular Technology, vol. 58, no. 8, (2009), pp. 3981-3987.

[7] R. Capata and A. Coccia, "Procedure for the design of a hybrid-series vehicle and the hybridization degree choice", Energies, no. 3, (2010), pp.450-461, doi:10.3390/en3.3.450.

[8] S. Barsali, C. Miulli and A. Possenti, "A control strategy to minimize fuel consumption of series hybrid electric vehicles”, IEEE Transactions on energy conversion, vol. 19, no. 1, (2004), pp. 187-195.

[9] G. Metin, B. Seta and J. D. Goering, "Sliding mode based powertrain control for efficiency improvement in series hybrid-electric vehicles", IEEE Transactions on Power Electronics, vol. 21, no. 3, (2006), pp.779-790.

[10] B. Seta, G. Metin and J. D. Goering, "A novel model validation and estimation approach for hybrid serial electric vehicles", IEEE Transactions on Vehicular Technology, vol. 56, no. 4, (2007), pp. 1485-1497.

[11] C. E. Nino-Baron, A. R. Tariq, G. Zhu and E. G. Strangas, "Trajectory optimization for the engine-generator operation of a series hybrid electric vehicle”, IEEE Transactions on Vehicular Technology, vol. 60, no. 6, (2011), pp. 2438-2447.

[12] V. Sezer, G. Metin and B. Seta, "A novel ECMS and combined cost map approach for high-efficiency series hybrid electric vehicles", IEEE Transactions on Vehicular Technology, vol. 60, no. 8, (2011), pp. 3557-3570.

[13] B. Geng, J. K. Mills and D. Sun, "Energy management control of microturbine-powered plug-in hybrid electric vehicles using the telemetry equivalent consumption minimization strategy", IEEE Transactions on Vehicular Technology, vol. 60, no. 9, (2011), pp. 4238-4248.

[14] Y. Zou, F. Sun, X. Hu, H. Peng, et al., "Combined optimal sizing and control for a hybrid tracked vehicle", Energies, no. 5, (2012), pp. 4697-4710, doi:10.3390/en5114697.

[15] S. G. Li, S. M. Sharkh, F. C. Walsh and C. N. Zhang, "Energy and battery management of a plug-in series hybrid electric vehicle using fuzzy logic", IEEE Transactions on Vehicular Technology, vol. 60, no. 8, (2011), pp. 3571-3585.

[16] C. Shen and C. Xia, "Control strategy of series hybrid electric vehicle based of improved dynamic programming”, Control Theory \& Applications, vol. 28, no. 3, (2011), pp. 427-432.

[17] W. Cheng, G. Shuying and L. Ling, "Development and application of serial hybrid electric powertrain system in the bus", Chinese Journal of Mechanical Engineering, vol. 45, no. 2, (2009), pp. 18-24.

\section{Authors}

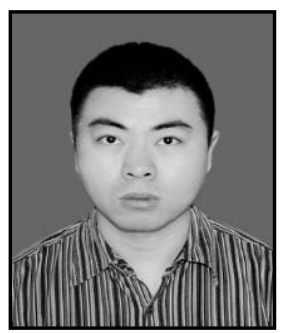

\section{Xiaogang Wu}

Xiaogang Wu was born in Harbin, China, in 1981. He received the B.S., M.S. and Ph.D. degrees in electrical engineering from the Harbin University of Science and Technology, Harbin, China, in 2003, 2006 and 2009, respectively. He is currently an Assoc. Professor of Power Electronics and Power Drive, Harbin University of Science and Technology. His research interest is the powertrain control of electric vehicles.

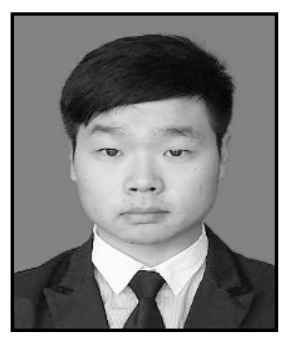

\section{Chen Hu}

Chen $\mathrm{Hu}$ was born in Heilongjiang, China, in 1991. He received the B.S. degree from Northeast Petroleum University, Daqing, China, in 2012. He is currently a postgraduate of Harbin University of Science and Technology. His research interest is the powertrain control of electric vehicles. 


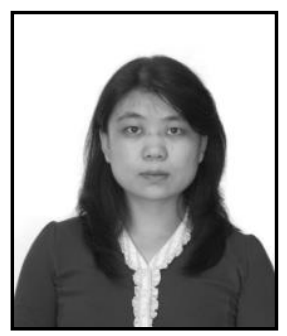

\section{Jiuyu Du}

Jiuyu $\mathrm{Du}$ received the Ph.D. degree from Beijing Institute of Technology, Beijing, China. She is currently an assistant researcher of department of automotive engineering, Tsinghua University. Her research interests are system configuration and modeling technology of electric vehicle, new type of powertrain performance analysis and evaluation.

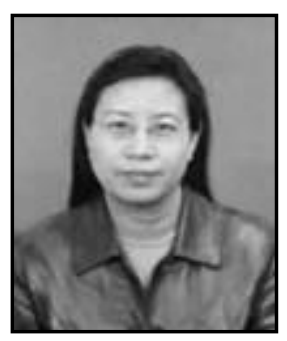

\section{Meilan Zhou}

Meilan Zhou received the Ph.D. degree from Harbin University of Science and Technology, Harbin, China, in 2006. She is currently a Professor of Power Electronics and Power Drive, Harbin University of Science and Technology. Her research interests are intelligent control and simulation, auto control system and automatic detection technology. 
International Journal of Control and Automation Vol.7, No.4 (2014) 